\title{
Determinants of Food Security and its Role of Market Access in Enhancing Food Security in Rural Ethiopia: A Case Study Among Rural Smallholder Farm Households of Gombora Woreda in Hadiya Zone, Ethiopia
}

\author{
Sanait Tadele Negese Tamirat
}

\begin{abstract}
The study was conducted in SNNPR; Hadiya Zone in Gombora Woreda to assess the status of smallholder farming household's food security, and its determinants including the role of market accessibility factors in increasing food security at smallholder farm households level. The data used for the study were obtained from 364 randomly selected sample households in the study area. The data for the study was collected from both primary and secondary sources. For the primary data collection, questionnaires was designed and pre-tested based on the objective of the study in the study area. The questionnaires schedule was tested at the farm level on 10 randomly selected farm households. The study was employed both descriptive and econometric data analysis methods. Binary logistic regression model was employed to analyze the market accessibility factors in enhancing food security at smallholder farm household's level. Results of econometric model showed that the age of household, education level, use of credit, monthly income, and distance to road, distance to market, extension services and crop diseases were significantly determining rural smallholder farm household's food security. The results suggest that local food security can be enhanced by creating off-farm employment opportunities, improved transportation facilities and road infrastructure. So, government should exhaustively work on promoting irrigation, providing credit, enhancing extension service and subsidize the farmers in the area of agricultural sector to solve the problem of food insecurity and should give due emphasis to female headed households to empower economically.
\end{abstract}

Keywords: Econometric Analysis, Food Security, Binary logistic regression model

DOI: $10.7176 / \mathrm{FSQM} / 100-05$

Publication date:August $31^{\text {st }} 2020$

\section{Introduction}

Food security is an important factor in terms of quantity and quality for all people of nation to continue its sustainable development. It is integration of three core dimensions i.e. food availability, accessibility and utilization. Problem is that Lack of food in long terms will lead to hunger and starvation that can cause death. Lack of food security is not only by insufficient supply of food, but also due to the lack of purchasing power and access at national and household's level [1]. Particularly, sub-Saharan Africa (SSA), there is food deficient due to different constraints; such as: droughts, increasing expenditure on food production and imports, falling export earnings and rapid population growth. The effect is not only incomes of agricultural producers but also on supplies of food and raw materials for industry, on employment, savings, government revenue, and on the demand for goods and services produced outside agriculture. According to the SSA countries, population growth has pressure on agricultural land and the size of land holding is inadequate to produce enough food for the whole smallholder farming households. This increases marginal land into cultivation, through affecting average yield per hectare. The need to enhance land and labor is becoming urgent [2].

Agriculture is by far the largest sector of Ethiopia's economy serving as a basis for the country's food security and source of livelihood for over $80 \%$ of its people. The sector accounts for about $50 \%$ of the Gross Domestic Product (GDP), $90 \%$ of the total export revenue, $85 \%$ employment of the country's labor force and accounts $70 \%$ of raw materials requirement of the country's industries, which is important four countries sustainable development [3]. Consequently, it has been the core element of the country's Agriculture Development Led Industrialization (ADLI) strategy for many years [4]. In spite of all this, access to off-farm sources of income is critical to the survival of the rural poor [5]. Agriculture sector is rainfall dependent; timing of rainfall is of critical importance. The right amount of rain at the right time is far more important than the use of fertilizer, improved seeds, agrochemical or irrigation. Where smallholder rural farm household's faces low incomes and assets due to unfavorable seasonal rainfall can mean destitution to household's to achieve food security.

According to the [6], food security can be defined as all people, at all times, have physical, social and economic access to sufficient, safe and nutritious food that meets their dietary needs and food preferences for an active and healthy life. In Ethiopia ensuring food security is country's greatest challenges. Commonly Ethiopia has made little progress in enhancing food security and countries face significant challenges related to enhancing food security. Increases food security; increases substantially of aggregate yields, increase effective land certification water harvesting schemes, introduction of successful extension activities like improved crop varieties and increasing adoption of some agricultural inputs, such as improved seed and fertilizer [7, 8, 9 \& 01]. 
The food security is complex phenomenon due to this there is complex food supply chain system and prevailing risks and vulnerabilities along the supply chain. Lack of proper food transport infrastructure and little access to food and market are some of the many factors that can affect food security. Food security at lower level may be enhanced by focusing on access to food and food distribution systems. Good food distribution system mainly depends on food and market access. Access of market is one of the important factors affecting rural food security. Producers and consumers at the same time, market access plays two-way function for smallholder farming rural households. On one hand they use the market to buy inputs or to sell farm produce while on the other hand, they use it to buy food and non-food items in order to sustain their living standards. Better infrastructure, easy market access and access to other institutional services such as extension and credit can play an important role in sustaining local food security through reduced transportation cost and food prices [11, 12 \& 13].

Like SSA countries, Ethiopia faces food shortage due to poor economy of the country. Depends up on state and extent of development of the natural resources food shortage varies from one area to another in the nation. The lack of food security is high and widespread mainly in rural area due to economic, social, environmental and human factors [14]. Amount of rainfall, quality of land and amount of crop that affects smallholder rural farm household food security level in the study area. Shortage of rainfall and declined soil fertility, intercropping main crops with cash crops is becoming difficult [15]. The major factors of food insecurity in the study Kebeles (Sage, Wera, Bole, First Ole, Second Ole and Wabo) are shortage of rain and erratic nature of rainfall distribution which leads to heavy soil erosion during rainy seasons which led to asset depletion of smallholder rural farm households in the study area. Per capita income growths are not sufficient to satisfy the demand of a growing population. Rate of population growth is growing due to cultural practices, lack of knowledge on family planning services, limited health service providers and socio-cultural influence. This implies the existence of structural, socio-economic, cultural, demographic and other factors increasing the poverty and seasonal food insecurity problem in the study area.

However, a few studies have been conducted focusing on the different dimensions of rural food security in smallholder rural farming households in Ethiopia, particularly, in Hadiya Zone and were little focus given to the role of market accessibility in increasing access to food and related food security of smallholder rural farming households of Hadiya zone. Systematic and adequate information on the role of market accessibility and related food security were not well identified. Further, in the study area there is no empirical study conducted on the role of market accessibility in increasing access to food and related food security of smallholder rural farming households. Therefore, this study was conducted to assess impact of market accessibility on rural household's food security along with causes of food insecurity. Specifically, this study was conducted to measure rural household's food security status and indicators in Smallholder rural areas of the Hadiya Zone, to identify the key causes of food insecurity among smallholder rural farm households and to determine the role of market accessibility along with other socio-economic factors in increasing smallholder rural farm household food security.

\section{Methods}

\section{Description of the Study Area}

The study was conducted in Gombora Woreda, Hadiya Zone, Southern Nations, Nationalities and Peoples Regional (SNNPR), Ethiopia. Gombora Woreda is located about $259 \mathrm{~km}$ south of Addis Ababa and 27km away from Hossana, the capital of Hadiya Zone and it is one of the 11Woredas of Hadiya Zone and geographically located between $7037^{\prime} \mathrm{N}$ latitude and $37040^{\prime} \mathrm{E}$ longitudes. The total population of the Woreda is 101,186, out of these, 50,651(50.06\%) is male and 50, $535(49.94 \%)$ is female. The Woreda has an agriculturally suitable land in terms of topography. Agro ecologically, the Woreda is classified as Dega 5\%, Weina Dega 51\% and kola 44\%. The annual rainfall varies from 1000 to $1085 \mathrm{~mm}$, while the annual mean temperatures also vary from $26^{\circ} \mathrm{c}$. The area receives a bimodal rainfall where the small rains are between March and April while the main rains are from July to September. During the main rains, all crops grown in the area are planted, including maize, teff, wheat, haricot bean, sorghum and millet. Rainfall during the main rains is unpredictable that most of the time crops fail due to uneven distribution of rainfall over the growing period. That is why the Woreda faces crop failures sometimes in years. The total land area of Woredas is 45,795 ha from that: Potentially cultivated land is $33,482.5$ ha $73.11 \%$, uncultivated land is 581.95 ha $(1.27 \%)$, grazing land is 714.5 ha $(1.56 \%)$, forest occupied land is 2,756 ha $(6.02 \%)$, it may be fertile land is $4,356.5$ ha $(9.51 \%)$ and others is 3,904 ha $(8.53 \%)$.

\section{Sampling Techniques}

A multi-stage stratified sampling technique was employed to select study sites and 364 smallholder rural farm households from three agro-climatic zones. In the first stage, to select study kebele we divided Woreda into three strata based on agro-climatic zones. In the second stage, we selected six kebele out of thirty kebeles using stratified purposive sampling technique. In the third stage: A total sample size 364 smallholder rural farm households were selected from each stratum using proportionate selecting procedures. The sample size was determined based on the formula given by [16], and allocation of sample size to each Kebele was made proportionate to the size of 
smallholder rural farm households of each stratum in the selected Kebeles.

$$
\mathrm{n}=\frac{\mathrm{N}}{1+\mathrm{N}\left(\mathrm{e}^{2}\right)}=\frac{4000}{1+0.05^{*} 0.05^{*}(4000)}=364
$$

Where $\mathrm{n}=$ the sample size, $\mathrm{N}=$ the population size, and $\mathrm{e}=$ the level of precision. $\mathrm{N}=$ the total number of households in the selected kebeles (4000 HHS), at 95\% confidence level and e= acceptable error margin 5\%. The strata were not identical in terms of kebeles numbers; a proportionate sample was drawn from each stratum using the formula.

$$
\mathrm{n}_{\mathrm{i}}=\frac{\mathrm{N}_{\mathrm{i}}}{\mathrm{N}}(\mathrm{n})
$$

Where $n_{i}=$ the total number of selected sample from each $i^{\text {th }}$ selected kebele. $\mathrm{N}_{\mathrm{i}}=$ the total number of household in the $\mathrm{i}^{\mathrm{th}}$ kebeles. $\mathrm{N}=$ the total number of households in the selected kebeles and $\mathrm{n}=$ the total sample size.

Table 1: Distribution of sample size by kebele

\begin{tabular}{lcc}
\hline Kebele & Number of households $\left(\mathrm{N}_{\mathrm{i}}\right)$ & Total Sample $\left(\mathrm{n}_{\mathrm{i}}\right)$ \\
\hline Sage $\left(\right.$ Kebele $\left._{1}\right)$ & & 61 \\
Wera $\left(\right.$ Kebele $\left._{2}\right)$ & 666 & 59 \\
Bole $\left(\right.$ Kebele $\left._{3}\right)$ & 650 & 59 \\
First Ole $\left(\right.$ Kebele $\left._{4}\right)$ & 649 & 61 \\
Second Ole $\left(\mathrm{Kebele}_{5}\right)$ & 675 & 61 \\
Wabo $\left(\right.$ Kebele $\left._{6}\right)$ & 670 & 63 \\
Total & 690 & 364 \\
\hline
\end{tabular}

$\mathrm{n}_{\mathrm{i}}=$ total number of households selected from kebele $\mathrm{I}(\mathrm{I}=1,2,3,4,5,6) ; \mathrm{N}_{\mathrm{i}}=$ total number of households in kebele i.

\section{Data Collection}

The data for study was collected from both primary and secondary sources. Cross-sectional data was collected from the survey of randomly selected smallholder rural farm households. For the primary data collection, specifically designed and pre- tested questionnaire based on the objective of the study, and trained data enumerators was used. The questionnaires schedule was tested at 18 randomly selected farm households in the study area. Both quantitative and qualitative information were collected. The data collection included households demographic, socioeconomic and environmental characteristics (age of household, sex structures of household, education level of household, extension service, use of credit, use of recommended agricultural inputs, attending farmer training center, monthly income, distance to road, distance to market, irrigation and water, and crop disease. Secondary information like population number, agricultural inputs and outputs, farm use pattern, rainfall amounts (annual mean and cropping season), temperature and agroecology, etc were also collected. The survey was carried out in the months of May and June 2018.

\section{Data Analysis Method}

The study employed both descriptive and econometric methods for data analysis. Accordingly, descriptive statistics were used to provide an overview of the overall data. In addition, inferential statistics (such as chi-square and t-tests) were employed to provide further insights on factors affecting smallholder farming household's food security and role of market access in enhancing food security. Specifically, we use chi-square tests for identifying associations between smallholder farming household's food security status and qualitative factors. Furthermore, ttest shall be used to check whether smallholder farming households' food securities are different from household's food insecurities in terms of selected quantitative factors, thereby searching for potential relationships. Next, we applied econometric methods to provide a more appropriate and in-depth analysis. More specifically, we employ Binary Logit model to assess status and determinants of among smallholder farming household's food security and role of market access in enhancing food security.

Determining food security status: There are number of different ways to assess food security [17]. Different studies [18 \& 19] used different methods to measure food security. Among various methods, the calorie intakes method is one of the most popular methods to measure the extent of food security, which is used in this study [20]. In next step, to measure the rural household food security status and indicators, we employed Dietary Intake Assessment (DIA). Because our targeted households have these characteristics i.e. i) they are smallholder rural farm households and belong to lowest income group; ii) they consider filling stomachs to maintain a subsistence level of living instead of choosing the food with the nutritional or taste values and iii) lastly, they are most vulnerable ones to be food insecure [1]. Dietary Intake Assessment (DIA) or Calorie Intake Method is a recall method for usually 7 days. This is a widely-used method for food security measurement. A household was considered food secure if respondents used to maintain this daily caloric threshold and was assigned value 1 and 
zero otherwise. The formula to measure the household food security status can be written as:

$$
\mathrm{RHFS}_{\mathrm{i}}=\sum_{i=1}^{n} \mathrm{FSi}-\mathrm{Th} \geq 0
$$

Where RHFS is the smallholder rural farm household food security for $\mathrm{i}^{\text {th }}$ household which takes value 1 if smallholder rural farm household is food secure and zero otherwise and th stands for the threshold level. The other food security measures as presented by various studies are as follows:

$$
\begin{gathered}
\mathrm{P}=\frac{1}{M} \sum_{i=1}^{m} G_{\mathrm{I}} \\
\mathrm{G}_{\mathrm{i}}=\left(\mathrm{FS}_{\mathrm{i}}-\mathrm{Th}\right) / \mathrm{Th}
\end{gathered}
$$

Where $\mathrm{P}$ shows the shortfall/surplus index, $\mathrm{G}_{\mathrm{i}}$ is the deficiency/surplus faced by $\mathrm{i}^{\text {th }}$ household, $\mathrm{FS}_{\mathrm{i}}$ is the average daily calorie available to the $i^{\text {th }}$ household, and $\mathrm{m}$ is the number of households that are food secure /food insecure.

Measuring food insecurity gaps: Food insecurity gap measured the extent at aggregate level to which households are below/above the food security line. In implementing food security policies and programs, the values of the index could be monitored over time and compared among different groups of the population. The Total Food Insecurity Gap may be calculated as:

$$
\mathrm{TFIG}=\frac{1}{M} \sum_{i=1}^{m} \frac{T h-\mathrm{FSi}}{T h}
$$

Where, TFIG is the total food insecurity gap, which indicates the depth of food insecurity among the food insecure smallholder rural farm households and $M$ is the number of food insecure smallholder rural farm households. The squared Food Insecurity Gap, which indicates the severity of food insecurity among smallholder rural farm households given as:

$$
\mathrm{SFIG}=\frac{1}{M} \sum_{i=1}^{m}\left(\frac{T h-\mathrm{FSi}}{T h}\right)^{2}
$$

Determining impact of market accessibility on food access: logistic regression was employed. In order to determine the impact of market accessibility and other socio-economic factors, we used binary logistic regression model. The general logistic model may be written as:

$$
\text { Logit }\left(\delta_{\mathrm{i}}\right)=\beta_{0}+\beta_{\mathrm{i}} \mathrm{X}_{\mathrm{i}}+\Omega \mathrm{i}
$$

Where; $\beta_{0}$ is the intercept, $X_{i}$ is the vector of explanatory variables used in the model and $\beta_{\mathrm{i}}$ shows the estimated coefficients of the explanatory variables. $\Omega \mathrm{i}$ is the error. Dependent Variable: Food Security status of the smallholder rural farm households. It takes value 1 if smallholder rural farm household is food secure and zero otherwise.

Table 2: Description of variables used in the binary logistic regression model

\begin{tabular}{lcc}
\hline Definition & Type & Expected sign \\
\hline \hline Education level in years of schooling (Edu) & Continuous & + \\
Age of household head (years) (Ageh) & Continuous & - \\
Participation in extension services $(1=$ Yes) (Pes) & Dummy/binary & + \\
Use of credit $(1=$ Yes) (Uc) & Dummy/binary & + \\
Sex of household head (1 Male) (Sexh) & Dummy/binary & + \\
Use of recommended agriculture inputs $(1=$ Yes) (Uri) & Dummy/binary & + \\
Attending training at farmers training center $(1=$ Yes) (Aft) & Dummy/binary & + \\
Monthly income (Mi) & Continuous & - \\
Distance to road (Dr) & Continuous & - \\
Distance to market (Dm) & Continuous & + \\
Irrigation water (Iw) & Dummy/binary \\
Crop diseases $(\mathrm{Cd})$ & Dummy/binary & - \\
\hline
\end{tabular}

\section{Results and Discussion}

\section{Description of Food Security Methods}

As regard to the age of smallholder rural farm household head, average age of the sample smallholder rural farm household head was found to be 46.29 years where the minimum is 20 and the maximum are 81 . According to education level of the smallholder rural farm household heads majority sample household heads are literate. The average level of the sample smallholder rural farm household head was found to be 6 years where the minimum is 0 and the maximum is 12 . The monthly average income of smallholder rural farm household was found US\$ 86 , maximum and minimum monthly smallholder rural farm household US\$ 86 and US\$ 250 respectively. The Mean distance to the paved road and output market was about 2 and 6 kilometers respectively. The minimum distance to the paved road and output market was about 1 and 4 kilometers respectively. The maximum distance to the paved road and output market was about 3 and 8 kilometers respectively. 
Table 3: Descriptive statistics of continuous variables

\begin{tabular}{lllll}
\hline Variable & Obs & Mean & Min & Max \\
\hline \hline Ageh & 364 & 46.29 & 20 & 81 \\
Edu & 364 & 6 & 0 & 12 \\
$\mathrm{Mi}$ & 364 & US 86 & US\$ 10 & US\$ 250 \\
$\mathrm{Dr}$ & 364 & $2 \mathrm{~km}$ & $1 \mathrm{~km}$ & $3 \mathrm{~km}$ \\
$\mathrm{Dm}$ & 364 & $6 \mathrm{~km}$ & $4 \mathrm{~km}$ & $8 \mathrm{~km}$ \\
\hline
\end{tabular}

Source: own computation based on data (2018)

\section{Determinants of rural smallholder farm household's food security}

Smallholder rural farm household's food security status Calorie intake method was used to compute the food security status of the smallholder rural farm households of the study area. Here it is important to mention that to compute per capita smallholder farm household caloric intake, this study did not directly collect information on dietary intake of their smallholder rural farm household's members. Instead this study used Adult Consumption Equivalents to compute the average dietary intake of each smallholder rural farm household's member of different age and gender which is the proportion to the dietary intake of the smallholder rural farm households. Age of the sample household head (Ageh): this variable affects rural smallholder farm household's food security negatively and significant at $1 \%$ level of significant $(\mathrm{P}=0.003)$ between rural smallholder farm household's food security and insecurity (table 5). The odds ratio (0.017) shows that odds ratio in favor of rural smallholder farm households food security decreases by a factor of 0.017 , as the age of the rural smallholder farm households head increases by 1 year (table 5). The education level of household head (Edu): this variable is a positive relationship with rural smallholder farm household's food security and significant at $5 \%$ of probability level $(\mathrm{P}=0.012)$ between rural smallholder farm household's food security and insecurity (table 5). The marginal effect is (0.165) implies that as the year of schooling of household heads increased by 1 grade, rural smallholder farm households head who educated is enhancing rural smallholder farm household's food security by $16.5 \%$ as compared to rural smallholder farm households head who are illiterate, other things kept constant. Education helped rural smallholder farm households to develop perception on food security.

Use of credit service of household head (Uc): this variable is a positive relationship with rural smallholder farm household's food security and significant at 5\% level of significant $(\mathrm{P}=0.024)$ between rural smallholder farm household's food security and insecurity (table 5). The The marginal effect is $(0.215)$ implies that the result is expected since use of credit service is major source of income for rural smallholder farm household's food security, hence a household's head who got credit is increasing rural smallholder farm household's food security by $21.5 \%$ as compared to household's head who did not get credit, other things kept constant. Monthly income of household head (Mi): it is positively related with rural smallholder farm household's food security and significant at $1 \%$ level of significant $(\mathrm{p}=0.002)$ between rural smallholder farm household's food security and insecurity (table $5)$. The marginal effect (0.080) this is that households head whose monthly income increase by 1 , rural smallholder farm household's food security increases by $8 \%$, other things kept constant. Distance to road (Dr): this variable is a negative relationship with rural smallholder farm household's food security and significant at $5 \%$ level of significant $(\mathrm{p}=0.035)$ between rural smallholder farm household's food security and insecurity (table 5). The Marginal effect is (-0.040) implies that the rural smallholder farm households distance to road increase by $1 \mathrm{Km}$, rural smallholder farm household's food security decreases by $4 \%$, other things kept constant. Distance to market $(\mathrm{Dm})$ : this variable is a negative relationship with rural smallholder farm household's food security and significant at $10 \%$ level of significant $(\mathrm{p}=0.071)$ between rural smallholder farm household's food security and insecurity (table 5). The Marginal effect is -0.230) implies that the rural smallholder farm households distance to market increase by $1 \mathrm{Km}$, rural smallholder farm household's food security decreases by $23 \%$, other things kept constant.

Participation in extension services (Pes): it is positively related with rural smallholder farm household's food security and significant at $1 \%$ level of significant $(\mathrm{p}=0.008)$ between rural smallholder farm household's food security and insecurity (table 5). The Marginal effect (0.231) this is that rural smallholder farm households head who is involved in extension services 1 times, rural smallholder farm household's food security increases by $23.1 \%$, other things kept constant. Crop diseases $(\mathrm{Cd})$ : this variable is a negative relationship with rural smallholder farm household's food security and significant at 5\% level of significant $(\mathrm{p}=0.024)$ between rural smallholder farm household's food security and insecurity (table 5). The Marginal effect is $(-0.232)$ implies that the crop diseases happened 1 times, rural smallholder farm household's food security decreases by $23.2 \%$, other things kept constant. 
Table 5: Determinants of rural smallholder farm household's food security

\begin{tabular}{lcccc}
\hline Variable & $\begin{array}{c}\text { Robust } \\
\text { Coefficient }\end{array}$ & $\begin{array}{c}\text { Odds } \\
\text { Ratio }\end{array}$ & $\mathrm{P}>|\mathrm{Z}|$ & Marginal effect \\
\hline Ageh & $-.9543515^{* * *}$ & 0.017 & 0.003 & -0.012 \\
Sexh & 0.534432 & 1.706 & 0.255 & 0.132 \\
Edu & $2.000964^{* *}$ & 0.272 & 0.012 & 0.165 \\
Uc & $2.512264^{* *}$ & 0.405 & 0.024 & 0.215 \\
Mi & $0.3248332^{* * *}$ & 1.389 & 0.002 & 0.080 \\
Aft & 0.1534501 & 1.162 & 0.720 & 0.372 \\
Uri & 1.720388 & 0.389 & 0.167 & 0.123 \\
Dr & $-0.626750^{* *}$ & 1.872 & 0.035 & -0.040 \\
Dm & $-2.632238^{*}$ & 0.536 & 0.071 & -0.230 \\
Iw & 0.2171265 & 1.205 & 0.434 & 0.047 \\
Pes & $0.9382242^{* * *}$ & 2.555 & 0.008 & 0.231 \\
Cd & $-0.8447838^{* *}$ & 2.573 & 0.024 & -0.232 \\
Cons & 0.0012353 & 1.859443 & $0.000^{* * *}$ & \\
\hline
\end{tabular}

Source: own computation based on data (2018).

Obs $=364$ Total No. of Independent Variables $=12 \quad{ }^{* * *} \mathrm{P}<0.01,{ }^{* *} \mathrm{P}<0.05$ and ${ }^{*} \mathrm{P}<0.10$

\section{Conclusion and Policy Implication}

In this study, we assessed the smallholder farming households' food security status and its determinants including role of market accessibility factors in defining food security at rural small farm households' level in Gombora district, Ethiopia. Both descriptive and econometrics methods were employed for data analysis. In particular, Binary logistic regression was used to evaluate the rural smallholder farming households' food security status and its determinants including role of market accessibility factors in defining food security at rural smallholder farm households' level. The econometric results showed that the age of household, education level, use of credit, monthly income, and distance to road, distance to market, extension services and crop diseases were significantly determining rural smallholder farm household's food security. Further, increase in food prices, crop disease, lack of water, changes in climate and small farming communities totally dependent on agriculture sector are major factors by rural smallholder farm households that may affect their livelihood and food security status.

Given these findings, a number of implications could emerge from our analysis up on which important suggestions could be made as key recommendations. Age of household, education level, use of credit, monthly income, extension services and crop diseases and more importantly market-related factors like distance to road and distance to market significantly influence the rural smallholder farm household's food security status. All this implies more investment and focus need to be given on food distribution system and infrastructure. Easy access to road, access to market and improvement in the infrastructure will not only reduce the transportation cost but it will also improve the availability of cheap food products at rural smallholder farm households. Further, it will also increase rural smallholder farm households' purchasing power and will improve food security status at rural smallholder farm households'. So a government has to create awareness about benefits of rural smallholder farm households' food security. Therefore, changing the attitudes of rural smallholder farmer households' is an important factor in enhancing food security at households' level. Increasing the number of cooperatives organization in the rural area in which the farmers will be able to get credit are bamsis in enhancing the rural smallholder farm households' food security. Thus, the credit facility should target poor farmers especially those who were increasing the level of food security due to lack of operating capital. The agricultural research and extension is a crucial factor in rural smallholder farm households' food security. In case of extension, a significant proportion of farmers had no formal education; the extension program should be targeted to the less educated farmers for its effective delivery through special training, seminars, field demonstrations, and technical support should be facilitated to enhance the rural smallholder farm households' food security. The improved access to diversified and qualified agricultural extension service still remains critically important for the food security.

\section{Reference}

1. FAO. (2009). Crop prospects and food situation. Rome: Food and Agricultural Organization.Available.

2. Khush G., Lee S., Cho, J.-I. and Jeon, J.S. (2012). Biofortification of Crops for Reducing Malnutrition. Plant Biotechnology Reports 6: 195-202.

3. MoFED. (2012). Ethiopian's progress towards eradicating poverty: An interim report on poverty analysis Study. Addis Ababa, Ethiopia.

4. ATA. (2013). Results of 2012 New Tef Technologies Demonstration Trials Draft Report VF. Addis Ababa, Ethiopia. $34 p$.

5. Creaswell. (2002). Livelihood Diversification in Southern Ethiopia. IDS working Paper. 
6. FAO. (2003). Trade reforms and food security. Food and Agriculture Organization: Rome.

7. Cochrane. (2017). Strengthening food security in rural Ethiopia. Doctoral Dissertation (Interdisciplinary Studies).

8. CSA. (2016). Agricultural sample survey 2015/2016, Vol. 1: Area and production of major crops. Central Statistical.

9. Tsedeke A, Bekele S, Abebe M, Dagne W, Yilma K, Kindie T, Menale K, Gezahegn G, Berhanu T and Tolera K. (2015). Factors that transformed maize productivity in Ethiopia. Food Security 7: 965-981.

10. Taffesse AS, Dorosh P, Gemessa SA. (2012). Crop production in Ethiopia: Regional patterns and trends. In Food and Agriculture in Ethiopia: Progress and Policy Challenges edited by P. Dorosh and S Rashid. University of Pennsylvania: Philadelphia.

11. IFAD. (2013). Market orientation and household food security. Rome, Italy: International Fund for Agricultural Development. Available at: www.ifad.org/hfs/thematic/rural/rural_4.htm assessed on June $14,2013$.

12. Minten. (1999). Infrastructure, market access and agricultural prices: Evidence for Madagascar. MSSD.

13. Simtowe F,Tembo D. (2019). The effects of market accessibility on household food security: Evidence.

14. Webb, P., Braun, J., Yohannes, Y. (1992). Famine in Ethiopia: Policy Implications of Coping Failure at National and Household levels. Research Report 92, IFPRI.

15. Degefa. (2005). Rural Livelihoods, Poverty and Food Insecurity in Ethiopia: A Case Study at Erenssa and Gabri Communities in Oromiya Zone, Amhara National Regional State. Doctoral Thesis. University of Trodheim.

16. Yamane, T. (1967). Statistics, an Introductory Analysis, 2nd Ed., New York: Harper and Row.

17. Cafiero C1, Melgar-Quiñonez HR, Ballard TJ, Kepple AW. (2014). Validity and reliability of food security measures. Ann N Y Acad Sci. 1331:230-48. doi: https://doi.org/10.1111/nyas.12594 PMID: 25407084.

18. Bashir MK, Naeem MK, Niazi SAK. (2010). Rural and peri-urban food security: a case of District Faisalabad of Pakistan. World Applied Sciences Journal. 9: 403-411. www.idosi.org/wasj/wasj9(4)/10.pdf.

19. Abebaw D, Fentie Y, Kassa B. (2010). The impact of a food security program on household food consumption in Northwestern Ethiopia: A matching estimator approach. Food Policy. 35: 286-293. https:// doi.org/10.1016/j.foodpol.2010.01.002.

20. Hussain A, Zulfiqar F, Saboor A. (2014). Changing food patterns across the seasons in rural Pakistan: analysis of food variety, dietary diversity and calorie intake. Ecology of Food and Nutrition. 53(2): 119- 141, https://doi.org/10.1080/03670244.2013.79207. 